\title{
ISSN 0103-5525
}

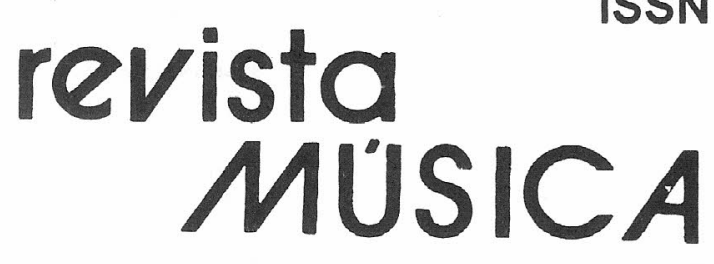

Vol. 8 - n. $1 / 2$ - maio/novembro 1997

\section{SUMÁRIO}

Nota do Editor

Maria Alice Volpe Irmandades e Ritual em Minas Gerais durante o Período Colonial - O Triunfo Eucarístico de 1733 5

Kilza Setti Orassom - Preces Cantadas dos Mbyá-Guaranis .. 57

Cynthia Priolli Seresta para Piano e Orquestra de CâmaraCulminância da Produção de Camargo Guarnieri no Gênero 67

Paulo Roberto Os Tangos Urbanos no Rio de Janeiro:

Peloso Augusto 1870-1920 - Uma Análise Histórica e Musical .. 105

Marco Antonio da O Uso Musical do Silêncio

Silva Ramos

Rubens Ricciardi Jdanov, Brecht, Eisler e a Questão do Formalismo 169

François Lesure Encontros com François Lesure. 207

Ricardo Tacuchian Quatro Décadas de Criação Musical para Piano (Resenha) 241 
Arnaldo Contier
(FFLCH - USP)

Flávia Toni

(IEB - USP)

Gilberto Mendes

(CMU - ECA - USP)

Jorge Coli

(UNICAMP)

Lorenzo Mammi

(FFLCII - USP)
Paulo Costa Lima

(UFB)

Régis Duprat

(CMU - ECA - USP)

Rodolfo Coelho de Souza

(Compositor)

Samuel Araújo

(UFRJ)

Silvio Augusto Crespo

(CMU - ECA - USP)

\author{
Comissão \\ Alfredo Bosi \\ José Eduardo Martins \\ Lorenzo Mammi \\ Marcos Branda Lacerda \\ Eliana Neves Araújo (Secretária)
}

Editor Responsável

José Eduardo Martins

Revisão

Vera Toledo Piza

Revista Música é uma publicaç̃̃o semestral (maio/novembro) editada pelo Departamento de Música da ECA-USP

O parecer favorável do Conselho Editorial não garante a publicação imediata dos trabalhos. Os artigos não publicados permanecem na Secretaria da Revista à disposiçāo dos autores.

Pede-se permuta

We ask for exchange

Revista Música - Departamento de Música da Escola de Comunicações e Artes da Universidade de São Paulo - Caixa Postal 8191 - São Paulo - SP - Brasil 